\title{
EVOLUÇÃO DO ÍNDICE PROTEOLÍTICO E DO COMPORTAMENTO REOLÓGICO DURANTE A VIDA DE PRATELEIRA DE LEITE UAT/UHT ${ }^{1}$
}

\author{
Ana Maria C. VIDAL-MARTINS², Bruna M. SALOTTI², Oswaldo D. ROSSI JUNIOR², Ana Lúcia B. PENNA ${ }^{3}$
}

\section{RESUMO}

A proteólise do leite UAT/UHT durante a estocagem à temperatura ambiente é um dos fatores limitantes de sua vida de prateleira. Neste trabalho, dois lotes de leite cru contendo 10 amostras cada e, posteriormente ao processamento, dois lotes de leite UAT/UHT contendo 25 amostras cada foram colhidos em um laticínio para a contagem de microrganismos psicrotróficos (leite cru) e para o estudo do comportamento reológico e o índice proteolítico (leite UAT/UHT durante 120 dias de estocagem). Para a contagem de microrganismos psicrotróficos, foi utilizada a técnica da contagem padrão em placas. Para a determinação do índice proteolítico, foi determinada a presença de glicomacropeptídeo livre por espectrofotometria a $470 \mathrm{~nm}$. A determinação dos parâmetros reológicos foi efetuada à temperatura ambiente, em quintuplicata em um reômetro de cone e placa. Houve aumento da proteólise no decorrer do armazenamento e aumento da viscosidade aparente após 60 dias de estocagem, provavelmente relacionados à presença de proteases de bactérias psicrotróficas do leite cru.

Palavras-chave: leite UAT/UHT, viscosidade aparente, proteólise.

\section{SUMMARY}

PROTEOLYTIC PROFILE AND RHEOLOGICAL BEHAVIOR DURING THE SHELF-LIFE OF UHT MILK. Proteolysis of UHT milk during storage at room temperature is a major factor limiting its shelf-life. In this work, two lots of 10 samples of raw milk each, and after manufacturing, two lots of UHT milk containing 25 samples each, were obtained from a dairy plant for the psychrotrophic microorganism count (raw milk) and to study the rheological behavior and proteolysis index (UHT milk during 120 days of storage time). The psychrotrophic count was carried out using the standard plate count method. The proteolysis index was determined by the presence of free glicomacropeptide using a spectrofotometer at $470 \mathrm{~nm}$. Rheological parameters were carried out five times the same lot at room temperature, using a cone and plate rheometer. There was an increase in proteolysis during the shelf-life and after 60 days of storage, an increase in the apparent viscosity, probably due to the presence of bacterial proteinases produced by psychrotrophic bacterial contaminants in the raw milk.

Keywords: UHT milk, apparent viscosity, proteolysis.

\section{1 - INTRODUÇÃO}

Atualmente, é crescente a preocupação do consumidor brasileiro com a qualidade dos alimentos e a conseqüente redução dos riscos à sua saúde e ao meio ambiente [20, 33]. Da grande variedade de alimentos disponíveis à população para consumo, o leite destaca-se pela sua rica constituição, sendo inclusive usado, em muitos casos, como a única fonte de alimento para os recém-nascidos [27].

A utilização do tratamento térmico para garantir a qualidade dos alimentos tem ocupado um espaço relevante na evolução da tecnologia alimentar. Devido à sua tecnologia, o leite tratado à ultra-alta temperatura (UAT ou UHT, do inglês ultra-high temperature) tornou-se um produto de destaque e de fácil comercialização e consumo [4].

Uma das principais características do leite UAT/UHT é sua extensa vida de prateleira (shelf-life) sem refrigeração, período no qual o produto apresenta características bacteriológicas, físicas e químicas aceitáveis [24]. Um produto pode ser considerado estável durante a estocagem por tanto tempo quanto ele permanecer um líquido homogêneo. Dois tipos de instabilidade física ocorrem durante a estocagem de produtos lácteos tratados pelo calor: sedimentação e/ou cremeação e geleificação. A sedimentação e a cremeação

\footnotetext{
${ }^{1}$ Recebido para publicação em 16/07/2004. Aceito para publicação em 31/08/2005 (001378).

${ }^{2} U N E S P$ - Departamento de Medicina Veterinária e Preventiva e Reprodução Animal - Jaboticabal.

${ }^{3}$ UNESP - Departamento de Engenharia e Tecnologia de Alimentos - São José do Rio Preto.
}

podem simplesmente ser relativas ao tamanho das partículas presentes imediatamente após a fabricação e acentuadas pela agregação de partículas durante a estocagem. A geleificação é sempre devido a algum tipo de processo de agregação durante a estocagem, mas não necessariamente de partículas. Se a agregação de partículas durante a estocagem acentuar a sedimentação e/ou cremeação, ou resultar em um gel, vai depender de muitos fatores. A extensão dos agregados emergentes e a fração do volume inicial de partículas são importantes fatores, tanto quanto o nível de agregação [19, 24].

O processo de produção do leite UAT/UHT inicia com a avaliação da matéria-prima (leite cru), padronização, pasteurização, aquecimento (esterilização), homogeneização, refrigeração, envase em embalagem asséptica, estocagem e distribuição [15]. O aquecimento é realizado em temperaturas de 130 a $150^{\circ} \mathrm{C}$ por 2 a 4 seg., que pode ser responsável pela desagregação das micelas de caseína, resultando em um aumento do índice proteolítico e alterações das propriedades reológicas do leite. Nesta fase o ponto de maior controle é o binômio tempo-temperatura, que garante a esterilização comercial; temperaturas abaixo da estabelecida são indesejáveis e acima podem causar problemas tecnológicos como alterações das proteínas, interferindo no sabor, geleificação, formação de sedimentos, perda do valor nutricional e escurecimento $[4,5]$.

A qualidade da maioria dos produtos lácteos está diretamente relacionada com a qualidade microbiana do leite cru utilizado como matéria-prima. Dependendo da temperatura, condições e extensão da estocagem do leite, vários 
grupos de microrganismos podem passar por um período de crescimento intensivo, produzindo altas concentrações de enzimas, particularmente lipases e proteinases. Dentre esses grupos destacam-se os microrganismos psicrotróficos [5] que, embora sejam destruídos pela esterilização, produzem enzimas proteolíticas e lipolíticas resistentes ao calor. Estas enzimas são produzidas quando a contagem de bactérias atinge $10^{6} \mathrm{UFC} / \mathrm{mL}$ ou mais, e se desenvolvem em resíduos ou depósitos em leite presentes em equipamentos e tubulações de laticínios mal-higienizados [7, 34].

A eficiência do processo de esterilização do leite UAT/UHT depende da temperatura de estocagem e método de esterilização. O leite esterilizado pelo processo de aquecimento direto (injeção direta de vapor no leite) torna-se instável e forma um gel quando estocado por algumas semanas em temperatura ambiente, sendo que permanece estável por um longo tempo quando estocado sob refrigeração. A homogeneização do leite após o tratamento térmico também exerce função importante, pois esta poderá ser responsável por um leve aumento da viscosidade, devido à quebra dos glóbulos de gordura e formação de subunidades com maior capacidade de hidratação, podendo apresentar volumes maiores que os dos glóbulos originais [26].

O teor de glicomacropeptídeo (GMP ou ácido siálico) em leite e derivados tem assumido características de importante marcador das ações proteolíticas sofridas, seja na condição de matéria-prima ou mesmo no monitoramento de etapas importantes do processo tecnológico do leite UAT/UHT. A determinação do GMP por espectrofotometria utilizando o método da ninidrina ácida possibilita também a detecção de possíveis fraudes por adição de soro de queijo a leites fluidos [12].

Assim como o índice proteolítico, a avaliação da viscosidade do leite UAT/UHT durante sua vida de prateleira também é utilizada na avaliação de desagregação ou despolimerização que pode ocorrer nos estágios iniciais da hidrólise de proteínas. A viscosidade também sofre ação de efeitos físico-químicos, como o $\mathrm{pH}$, temperatura, teor de sólidos, tamanho de partículas e umidade [6]. As características de viscosidade e de consistência de um produto podem determinar sua aceitação ou não por parte do consumidor. Estas também são importantes durante o processamento, até mesmo na determinação de parâmetros do processo. O conhecimento das propriedades reológicas é importante para o desenvolvimento contínuo de produtos e processos, equipamentos, manuseio e controle de qualidade. Uma vez que em muitas operações e tratamentos ocorrem mudanças das características do produto, é também importante conhecer como a viscosidade varia com o tratamento utilizado.

Idealizou-se o presente estudo com os objetivos de determinar o número de microrganismos psicrotróficos presentes no leite cru e de acompanhar a vida de prateleira deste produto após o tratamento térmico por ultra-alta temperatura (leite UAT/UHT), analisando amostras no dia de sua fabricação e após 30, 60, 90 e 120 dias para verificar possíveis alterações de viscosidade e índice proteolítico.

\section{2 - MATERIAL E MÉTODOS}

As amostras de leite foram colhidas em uma indústria com capacidade para produção de 450 mil litros de leite UAT/UHT por dia, situada no estado de São Paulo, submetida ao controle higiênico-sanitário permanente, através do Serviço de Inspeção Federal (SIF). O processo de beneficiamento inclui a pasteurização seguida do processo por ultra-alta temperatura (UAT/UHT) através do sistema de aquecimento direto (injeção direta de vapor no leite). Para a realização do presente trabalho foram realizadas duas colheitas (lotes), uma em janeiro e outra em abril de 2003, sendo que cada uma delas se constituiu de 10 amostras de leite cru e 25 amostras de leite UAT/UHT. As amostras de leite cru foram colhidas em frascos de $500 \mathrm{~mL}$ esterilizados e mantidas a $4^{\circ} \mathrm{C}$, e após o processamento térmico (UAT/UHT) desta matéria-prima e envase, foram colhidas as amostras de leite UAT/UHT, que foram armazenadas em temperatura ambiente e transportadas para o laboratório para análises.

\section{1 - Contagem padrão em placas de microrganismos psicrotróficos no leite cru}

Primeiramente foram preparadas as diluições das amostras pipetando-se, assepticamente, $25 \mathrm{~mL}$ da amostra, e transferindo para um frasco tipo Erlenmeyer contendo $225 \mathrm{~mL}$ de água peptonada 0,1\% esterilizada (diluição $10^{-1}$ ). A partir desta diluição, foram preparadas diluições decimais até $10^{-6}$, empregando-se o mesmo diluente.

Após a realização das diluições decimais, foram adicionados de 15 a $17 \mathrm{~mL}$ de ágar padrão fundido e resfriado à temperatura em torno de $45^{\circ} \mathrm{C}$ em placas de Petri esterilizadas. Após a solidificação do ágar em temperatura ambiente, foi realizada a semeadura em superfície, onde $0,1 \mathrm{~mL}$ de cada diluição foi depositado na superfície do ágar e espalhado com alça de Drigalski. Em seguida, as placas foram incubadas a $7^{\circ} \mathrm{C}$ por 10 dias [1]. Essas determinações foram realizadas em duplicata. As contagens foram realizadas em contador de colônias, segundo técnica padrão, em placas com 25 a 250 colônias. Na contagem dos microrganismos psicrotróficos, além do número de colônias ser multiplicado pelo fator de diluição das placas correspondentes, também foi multiplicado por 10, pois foi utilizado apenas $0,1 \mathrm{~mL}$ de cada diluição.

\section{2 - Determinação do índice proteolítico (presença de GMP-glicomacropeptídeo livre por espectrofotometria a $470 \mathrm{~nm}$ ) do leite UAT/UHT}

Nesta avaliação, utilizou-se para precipitação protéica uma solução de ácido tricloroacético (TCA) a 24\% em quantidades iguais ao leite $(20 \mathrm{~mL})$. Após homogeneização e repouso de 30 minutos, a mistura foi filtrada em papel de filtro. Foram tomados $10 \mathrm{~mL}$ do filtrado e adicionados de $1 \mathrm{~mL}$ de ácido fosfotúngstico (PTA) a $20 \%$. Após centrifugação a $3500 \mathrm{rpm}$ por 10 minutos, desprezou-se o sobrenadante e $5 \mathrm{~mL}$ de álcool etílico $95 \%$ 
foram adicionados (para eliminar resíduos de lactose) e novamente submeteu-se à centrifugação. Utilizou-se somente o precipitado desta mistura, ao qual foram adicionados $2 \mathrm{~mL}$ de ácido acético glacial e $1 \mathrm{~mL}$ do reagente de ninidrina ácida. Após a homogeneização, foi feito o aquecimento em banho-maria fervente por exatos 10 minutos. A solução foi resfriada em banho-maria com água e gelo, e posteriormente foi realizada a leitura da absorbância espectrofotométrica, no comprimento de onda de $470 \mathrm{~nm}$, em duplicatas. Os resultados das leituras foram transformados em concentração ( $\mu \mathrm{g}$ de ácido siálico/mL amostra), utilizando-se a curva padrão previamente elaborada com ácido siálico puro. Esse método permite a quantificação da liberação da fração GMP (ou de ácido siálico) da א-caseína, conseqüentemente permitindo uma estimativa indireta das alterações do índice proteolítico sofridas pelas amostras [11].

\section{3 - Determinação dos parâmetros reológicos do leite UAT/UHT}

Os parâmetros reológicos foram obtidos em quintuplicata usando-se um reômetro de cone e placa Brookfield (Stoughton, USA), modelo RVDV III, através da relação entre a taxa de deformação e tensão de cisalhamento das amostras. O reômetro possui uma camisa termostatizada situada ao redor do arranjo cone e placa, em cujo interior circula água para o resfriamento ou aquecimento, permitindo um maior controle da temperatura.

O aumento da tensão de cisalhamento foi obtido pelo aumento da rotação, a partir da variação contínua da velocidade angular do cone. Foram utilizadas rotações de 200 a $250 \mathrm{rpm}$, com acréscimos de 2,5 rpm a cada 10 segundos, 0,5 mL de amostra e cone CP 40. A taxa de deformação foi determinada usando-se um programa computacional (Brookfield Reocalc for Windows) que emprega as seguintes equações:

$$
\begin{aligned}
& \dot{\gamma}=\frac{\omega}{\sin \alpha} \\
& \tau=\frac{\mathrm{T}}{\frac{2}{3} \pi \mathrm{r}^{3}}
\end{aligned}
$$

em que:

$\dot{\gamma}=$ taxa de deformação $(1 / \mathrm{s}) ; \tau=$ tensão de cisalhamento $(\mathrm{Pa}) ; \mathrm{T}=$ torque;

$\omega=$ velocidade angular do cone $(\mathrm{rad} / \mathrm{s}) ; \mathrm{rad} / \mathrm{s}=(2 \pi / 60)$ $\mathrm{rpm} ; \alpha=$ ângulo do cone (rad);

$\mathrm{r}=$ raio do cone.

A descrição do comportamento reológico foi feita utilizando-se o modelo reológico de Ostwald de Waele (Lei da Potência), com auxílio do programa Origin versão 5.0, considerando-se a colheita e o tempo de estocagem. A viscosidade aparente foi calculada na taxa de deformação $100 \mathrm{~s}^{-1}$.

\section{4 - Análise estatística}

A análise de variância (ANOVA) dos resultados experimentais foi realizada a partir de um delineamento inteiramente casualizado (DIC), com a utilização do teste de Tukey, considerando-se um nível de significância $\mathrm{p}<0,05$, utilizando o programa computacional ESTAT, versão 2.0.

\section{3 - RESULTADOS E DISCUSSÃO}

Na Tabela 1 estão descritos os resultados das contagens de microrganismos psicrotróficos do leite cru. Através dos resultados pôde-se verificar que a média da população de microrganismos psicrotróficos encontrada nas amostras da colheita $\mathrm{A}$ foi superior àquela encontrada na colheita $\mathrm{B}$, sendo a primeira de $2,0 \times 10^{9} \mathrm{UFC} / \mathrm{mL}$ e esta última de 4,4 $\mathrm{x} 10^{7} \mathrm{UFC} / \mathrm{mL}$. Estes valores estão intimamente relacionados ao grau de contaminação inicial e ao binômio tempo x temperatura em que o leite permaneceu desde a ordenha até o processamento. Esta carga microbiana presente no leite cru tem influência das estações do ano, das práticas de produção e manuseio na propriedade rural, localização geográfica, temperatura de permanência do leite e distância do transporte entre a propriedade rural e o local de beneficiamento [30].

TABELA 1 - População de microrganismos psicrotróficos das amostras de leite cru das colheitas A e B

\begin{tabular}{lcc}
\hline \multirow{2}{*}{$\mathbf{N}^{\circ}$ de amostras } & \multicolumn{2}{c}{$\begin{array}{c}\text { População de microrganismos } \\
\text { psicrotróficos em UFC/mL }\end{array}$} \\
\cline { 2 - 3 } & Colheita A & Colheita B \\
\hline 1 & $4,7 \times 10^{8}$ & $2,0 \times 10^{7}$ \\
2 & $3,0 \times 10^{9}$ & $5,0 \times 10^{7}$ \\
3 & $3,0 \times 10^{9}$ & $4,0 \times 10^{6}$ \\
4 & $2,6 \times 10^{9}$ & $6,0 \times 10^{7}$ \\
5 & $3,8 \times 10^{9}$ & $1,0 \times 10^{7}$ \\
6 & $5,1 \times 10^{8}$ & $1,0 \times 10^{7}$ \\
7 & $2,3 \times 10^{8}$ & $1,7 \times 10^{8}$ \\
8 & $4,0 \times 10^{8}$ & $8,0 \times 10^{7}$ \\
9 & $2,6 \times 10^{9}$ & $2,0 \times 10^{7}$ \\
10 & $3,0 \times 10^{9}$ & $2,0 \times 10^{7}$ \\
\hline Média & $2,0 \times 10^{9}$ & $4,4 \times 10^{7}$ \\
\hline
\end{tabular}

Na Tabela 2 estão descritos os resultados do índice proteolítico do leite UAT/UHT, determinado através da quantificação do ácido siálico, durante 120 dias de vida de prateleira dos dois lotes (colheitas A e B). Houve um aumento da proteólise no decorrer do armazenamento. Esta proteólise está relacionada com a quebra da caseína pela ação das proteases bacterianas, originárias principalmente das bactérias psicrotróficas presentes no leite cru que, após o tratamento UAT/UHT, são eliminadas, porém as enzimas termorresistentes continuam atuando lentamente sobre as proteínas durante o armazenamento do leite UAT/UHT. ORTIN-RODRIGUEZ e SANCHEZALGABA [25] também verificaram um aumento linear da quantidade de ácido siálico livre durante a vida de prateleira do leite UAT/UHT. 
TABELA 2 - Índice proteolítico do leite UAT/UHT durante 120 dias de vida de prateleira

\begin{tabular}{lcc}
\hline $\begin{array}{l}\text { Vida de prateleira } \\
\text { (dias) }\end{array}$ & \multicolumn{2}{c}{ Índice proteolítico $(\mu \mathrm{g}$ de ácido siálico/mL) } \\
\cline { 2 - 3 } & Colheita A & Colheita B \\
\hline 0 & $5,12^{\mathrm{eB}}$ & $6,48^{\mathrm{dA}}$ \\
30 & $11,66^{\mathrm{AA}}$ & $9,69^{\mathrm{CA}}$ \\
60 & $15,59^{\mathrm{CA}}$ & $12,39^{\mathrm{bB}}$ \\
90 & $19,45^{\mathrm{bA}}$ & $10,10^{\mathrm{CB}}$ \\
120 & $24,70^{\mathrm{AA}}$ & $17,78^{\mathrm{aB}}$ \\
\hline
\end{tabular}

*média de duas determinações. abcde Letras diferentes na mesma coluna indicam diferença significativa $(p>0,05)$ durante a vida de prateleira. ${ }^{A B}$ Letras diferentes na mesma linha indicam diferença significativa $(p>0,05)$ entre as colheitas

Na colheita A, o índice proteolítico foi aumentando no decorrer do armazenamento de maneira gradativa, de 5,12 a 24,70 $\mu$ g de ácido siálico/mL. A análise de variância mostrou que este aumento foi significativo durante todo o período de armazenamento, como mostram os dados da Tabela 2. Em trabalho semelhante, KONING et al. [19] verificaram um aumento da atividade proteolítica do leite UAT/UHT (tratamento direto) somente após 60 dias de vida de prateleira. Na colheita B também pôde ser notado um aumento significativo do índice proteolítico ao longo dos 120 dias de estocagem.

A maior contagem de microrganismos psicrotróficos na matéria-prima (leite cru) usada na elaboração do leite UAT/UHT na colheita A $\left(2,0 \times 10^{9} \mathrm{UFC} / \mathrm{mL}\right)$ comparada com a colheita $\mathrm{B}\left(4,4 \times 10^{7} \mathrm{UFC} / \mathrm{mL}\right)$, conforme descrito na Tabela 1, pode explicar o maior índice proteolítico observado na colheita A. Segundo SANTOS e LARANJA da FONSECA [29], a atividade enzimática dos psicrotróficos passa a ter grande importância quando as contagens ultrapassam $10^{6} \mathrm{UFC} / \mathrm{mL}$.

As proteases são capazes de hidrolisar toda a caseína disponível no leite em peptídeos solúveis. O efeito direto desta proteólise é o aparecimento de sabor amargo no leite devido à presença de peptídeos com esta característica sensorial [22]. As proteases de origem psicrotrófica apresentam capacidade de coagular a proteína do leite e possuem atividade hidrolítica em várias frações da caseína, apresentando, no entanto, baixa atividade degradativa sobre as proteínas do soro. A fração protéica representada pela caseína é facilmente degradada devido à sua estrutura não helicoidal [29].
No estudo realizado por SNOEREN, VAN RIEN e BOTH [31], a degradação da $\beta$ e $\alpha_{\text {s }}$-caseína originou-se sem considerar a atividade das proteinases bacterianas (a quebra destas proteínas deve ter ocorrido primeiramente pela plasmina); porém, SNOEREN e BOTH [32] detectaram quebra א-caseína no leite esterilizado pelo método UAT/UHT indireto elaborado com leite cru contaminado, no qual a plasmina foi completamente inativada. Estas observações sugerem que somente algumas das proteinases bacterianas altamente estáveis ao calor atacam a $\beta$-caseína, pelo menos no leite tratado termicamente.

A к-caseína localizada na superfície da micela de caseína é preferencialmente hidrolisada, e esta hidrólise causa o desenvolvimento de gosto amargo e induz o aumento da viscosidade, com eventual formação de gel do leite UAT/ UHT [8, 10], quando submetido a prolongado período de armazenamento [23].

Os resultados dos parâmetros reológicos descritos na Tabela 3 mostram que ocorreu um aumento no índice de consistência e na viscosidade aparente e diminuição no índice de comportamento do escoamento durante o armazenamento. Este comportamento também foi observado por AL-KANHAL, ABU-LEHIA e AL-SALEH [3], que relatam o aumento da viscosidade durante o período de estocagem do leite UAT/UHT. O nível de sedimentação foi baixo em todas as amostras e aumentou com o aumento do tempo de estocagem e da temperatura. McKELLER et al. [21] observaram aumento na viscosidade aparente e geleificação em leite de laticínios que usavam o método direto de esterilização 6 a 10 semanas após o desenvolvimento significativo de amargor.

ENRIGHT et al. [9] também observaram aumento da viscosidade aparente durante a estocagem de leite UHT, porém o aumento não foi considerado significativo.

Na colheita A, o índice de consistência $(K)$ variou de 1,174 a $21,756 \mathrm{mPa} . \mathrm{s}^{\mathrm{n}}$ para as curvas ascendentes e de 1,172 a $3,098 \mathrm{mPa} . \mathrm{s}^{\mathrm{n}}$ para as curvas descendentes. As diferenças observadas entre a curva de ascendência e descendência com a formação de uma curva de histerese demonstram a degradação estrutural da amostra, causada pelo cisalhamento contínuo.

A viscosidade aparente $(\mu)$, na colheita $\mathrm{A}$, variou de 1547,633 a $5828,799 \mathrm{mPa}$ na curva ascendente e de

TABELA 3 - Parâmetros reológicos do leite UAT/UHT durante 120 dias de vida de prateleira

\begin{tabular}{|c|c|c|c|c|c|c|c|c|c|}
\hline \multirow{2}{*}{ Colheita } & \multirow{2}{*}{ Estocagem } & \multicolumn{4}{|c|}{ Ciclo ascendente } & \multicolumn{4}{|c|}{ Ciclo descendente } \\
\hline & & $\mathbf{K}$ & $\mathrm{n}$ & $\mu$ & $\mathbf{R}^{2}$ & $\mathbf{K}$ & $\mathbf{N}$ & $\mu$ & $\mathbf{R}^{2}$ \\
\hline \multirow{5}{*}{ A } & 0 & $1,174^{b}$ & $1,060^{a}$ & $1547,633^{c}$ & 0,990 & $1,172^{d}$ & $1,066^{\mathrm{a}}$ & $1588,282^{c}$ & 0,976 \\
\hline & 30 & $1,546^{b}$ & $1,020^{a}$ & 1695,155 bc & 0,993 & $1,577^{\mathrm{cd}}$ & $1,014^{a b}$ & $1682,022^{c}$ & 0,994 \\
\hline & 60 & $2,070^{b}$ & $1,016^{a b}$ & $2228,283^{b}$ & 0,963 & $2,040^{b c}$ & $1,009^{a b}$ & $2126,328^{b}$ & 0,922 \\
\hline & 90 & $2,545^{b}$ & $0,955^{b}$ & $2068,654^{b}$ & 0,987 & $2,555^{a b}$ & $0,912^{\mathrm{c}}$ & $1703,691^{c}$ & 0,991 \\
\hline & 120 & $21,756^{\text {a }}$ & $0,714^{\mathrm{c}}$ & 5828,799 a & 0,989 & $3,098^{a}$ & $0,975^{b}$ & $2761,095^{a}$ & 0,983 \\
\hline \multirow{4}{*}{ B } & 0 & $1,304^{b}$ & $1,060^{a}$ & $1719,007^{b}$ & 0,981 & $0,474^{c}$ & $1,193^{a}$ & $1152,865^{b}$ & 0,987 \\
\hline & 60 & $2,574^{a}$ & $0,941^{b}$ & $1961,591^{a}$ & 0,984 & $2,280^{a}$ & $0,956^{b}$ & $1861,808^{a}$ & 0,981 \\
\hline & 90 & $2,365^{a}$ & $0,965^{b}$ & $2012,941^{\mathrm{a}}$ & 0,987 & $1,744^{b}$ & $1,010^{b}$ & $1826,192^{a}$ & 0,996 \\
\hline & 120 & $2,365^{a}$ & $0,961^{b}$ & $1972,023^{a}$ & 0,987 & $1,860^{a b}$ & $0,997^{\mathrm{b}}$ & $1834,480^{a}$ & 0,977 \\
\hline
\end{tabular}

$\mathrm{K}$ - índice de consistência (mPa.s $\mathrm{s}^{\mathrm{n}}$; $\mathrm{n}$ - índice de comportamento do escoamento (adimensional); $\mu$ - viscosidade aparente (mPa); $\mathrm{R}^{2}$ - coeficiente de determinação; abcde Letras $\mathrm{K}$ - indice de consistência $\left(\mathrm{mPa} \cdot \mathrm{s}^{\mathrm{n}}\right) ; \mathrm{n}$ - índice de comportamento do
diferentes na mesma coluna indicam diferença significativa $(\mathrm{p}>0,05)$ 
1588,282 a 2761,095 mPa na descendente. Durante o armazenamento, observou-se um aumento significativo da viscosidade aparente, atingindo o valor máximo aos 120 dias de estocagem, como pode ser observado na Tabela 3.

Na colheita B, o índice de consistência (K) variou de 1,304 a 2,360 $\mathrm{mPa} . \mathrm{s}^{\mathrm{n}}$ para as curvas ascendentes e de 0,474 a 1,860 mPa. $\mathrm{s}^{\mathrm{n}}$ para as curvas descendentes. A viscosidade aparente, na colheita B, variou de 1719,007 a 1972,023 mPa na curva ascendente e de 1152,865 a $1834,480 \mathrm{mPa}$ na descendente. $\mathrm{O}$ aumento da viscosidade foi significativo entre 0 e 60 dias. Após este período, a variação não foi considerada significativa, como mostra a Tabela 3.

A proteólise do leite UAT/UHT durante a estocagem em temperatura ambiente é um dos fatores mais importantes limitando sua vida de prateleira através de mudanças em seu sabor e textura. A textura é caracterizada pelo aumento na viscosidade, levando, em alguns casos, à formação de gel. As enzimas responsáveis pela proteólise são: a proteinase alcalina nativa do leite, plasmina e proteinases extracelulares bacterianas, termoestáveis, produzidas por bactérias psicrotróficas contaminantes do leite antes do processamento térmico. Estas proteinases reagem diferentemente com as proteínas do leite e produzem diferentes peptídeos no leite UAT/UHT [8].

O aumento da viscosidade aparente pode também estar relacionado à associação de $\beta$-lactoglobulina desnaturada com micelas de caseína no leite UAT/UHT, conforme observado por ENRIGHT et al. [9] usando a técnica de imunodetecção das proteínas do soro. A microscopia eletrônica de transmissão revelou pequenas cadeias de partículas submicelares e agregados de partículas micelares ligados transversalmente em leite cru refrigerado, após 84 dias de estocagem.

Até 30 dias de estocagem, o leite UAT/UHT apresentou um comportamento newtoniano $(n=1)$, o que significa uma relação linear entre taxa de deformação e tensão de cisalhamento, ou seja, a viscosidade é constante. Porém, após 60 dias de vida de prateleira, o leite UAT/UHT apresentou um comportamento pseudoplástico $(n<1)$, ou seja, a viscosidade aparente diminui com o aumento da taxa de deformação. Isto demonstra que o aumento da viscosidade aparente no decorrer da vida de prateleira resultou em mudança no comportamento do fluido durante os 120 dias de estocagem.

Na colheita A observou-se aumento significativo do índice de consistência e proteolítico durante o armazenamento, sendo que o maior aumento foi aos 120 dias, quando o índice de consistência atingiu 21,756 $\mathrm{mPa} \cdot \mathrm{s}^{\mathrm{n}}$ (ascendente) e 3,098 $\mathrm{mPa} \cdot \mathrm{s}^{\mathrm{n}}$ (descendente) e o índice proteolítico atingiu 24,70 $\mu \mathrm{g}$ de ácido siálico/mL. Porém, CELESTINO, IYER e ROGINSKI [7] verificaram um aumento na viscosidade (mensurada a $25^{\circ} \mathrm{C}$ ) do leite UAT/UHT após 90 dias de armazenamento, sendo que SUR e JOSHI [35] não verificaram alterações nos valores da viscosidade do leite UAT/UHT analisado durante 5 meses.

KELLY e FOLEY [16] observaram aumento da viscosidade aparente imediatamente após o tratamento do leite
UAT/UHT. A viscosidade decresceu e estabilizou até depois de 100 dias, quando um aumento na viscosidade foi observado. O maior aumento na viscosidade foi observado para amostras com maior contagem de células somáticas adicionadas de plasminogênio, que subseqüentemente geleificaram. Este aumento na viscosidade precedendo a geleificação foi também observado por KOHLMANN et al. [18]. Um decréscimo inicial na viscosidade foi observado para leite esterilizado UAT/UHT e leite concentrado, seguido por um período em que a viscosidade mudou drasticamente e, posteriormente, apresentou um nítido aumento, um pouco antes da geleificação. Tal observação é, entretanto, uma simplificação, uma vez que vários tipos de géis podem ser formados, variando de fraco e transparente para o semelhante ao produzido pela renina [14].

Quando a presença de psicrotróficos é elevada o suficiente para produzir enzimas proteolíticas até atingir um índice proteolítico próximo a $20 \mu \mathrm{g}$ de ácido siálico por $\mathrm{mL}$, o índice de consistência poderá aumentar significativamente durante a vida de prateleira do leite UAT/UHT [10]; tal fato pôde ser observado com clareza aos 120 dias da colheita A, onde o índice proteolítico atingiu $24,70 \mu \mathrm{g}$ de ácido siálico/mL e o índice de consistência na curva ascendente foi de 21,756 mPa.s ${ }^{\mathrm{n}}$. Segundo ROBINSON e PHILL [28] e DATTA e DEETH [8], ocorrem alterações nas características sensoriais e nutritivas durante o armazenamento do leite UAT/UHT à temperatura ambiente. Também podem ser observadas alterações na viscosidade que, às vezes, conduzem a geleificações. Estas alterações são decorrentes de atividades enzimáticas, principalmente enzimas extracelulares e termorresistentes, particularmente lipases e proteases, produzidas por bactérias psicrotróficas contaminantes do leite antes do processamento térmico. Assim sendo, a vida útil do produto está diretamente relacionada com a qualidade higiênica da matéria-prima, que pode ser considerada comprometida conforme dados da Tabela 1 .

Na colheita B, o índice de proteolítico aumentou durante a estocagem e atingiu $17,78 \mu \mathrm{g}$ de ácido siálico/mL aos 120 dias de armazenamento. Tal comportamento também foi verificado no índice de consistência. Apesar do nítido aumento da viscosidade aparente em ambas as colheitas, não foi observada a geleificação do produto durante o período de estocagem por 120 dias. ALAIS [2] relata que o processo de geleificação do leite UAT/UHT se desencadeia lentamente, uma diminuição inicial da viscosidade precede um período estável, seguido de um aumento da viscosidade que precede a geleificação. Este processo surge depois de um período de armazenamento variável, segundo a temperatura, 3 meses a $30^{\circ} \mathrm{C}$ e 5 a 6 meses a $20^{\circ} \mathrm{C}$. KODAK e ZADOW [17] sugerem que a geleificação por envelhecimento segue um mecanismo de dois estágios, compreendendo uma proteólise das proteínas do leite, seguido por um segundo período quando mudanças físico-químicas induzidas pela estocagem afetam a agregação das micelas desestabilizadas. Estas mudanças ocorrem lentamente e provavelmente são afetadas pela temperatura. A estabilidade do leite UAT/UHT também é influenciada por efeitos sazonais e pelo teor de proteínas do leite [13]. 


\section{4 - CONCLUSÕES}

Durante o armazenamento do leite UAT/UHT houve aumento do índice proteolítico e da viscosidade aparente durante a estocagem, relacionado à presença de proteases produzidas por bactérias psicrotróficas contaminantes no leite cru. No início da estocagem, o leite UAT/UHT foi caracterizado como fluido newtoniano, modificando para fluido pseudoplástico ao longo da estocagem.

\section{5 - REFERÊNCIAS BIBLIOGRÁFICAS}

[1] AMERICAN PUBLIC HEALTH ASSOCIATION (APHA). Committee on microbiological methods for foods. Compendium of Methods for the Microbiological Examination of Foods. Washington: American Public Health Association, 1992.

[2] ALAIS, C. Ciencia de la Leche: Principios de Técnica Lechera. Barcelona: Reverte. 1985.

[3] AL-KANHAL, H.A.; ABU-LEHIA, I.H; AL-SALEH, A.A. Changes in the quality of fresh and recombined ultra high temperature treatment milk during storage. Int. Dairy J., v. 4, n. 3, p. 221-236, 1994.

[4] BASTOS, M.S.R. Leite longa vida UHT: Aspectos do processamento e identificação dos pontos críticos de controle. Hig. Aliment., v. 13, n. 66/67, p. 32-36, 1999.

[5] BURTON, H. Ultra-High Temperature Processing of Milk and Milk Products. London: Elsevier Applied Science Publishers, 1988.

[6] CAMPOS, S.D.S.; GONÇALVES, J.R.; MORI, E.E.M.; GASPARETTO, C.A. Reologia e Textura de Alimentos. Campinas: ITAL. 1989.

[7] CELESTINO, E.L.; IYER, M.; ROGINSKI, H. Reconstituted UHT-treated milk: effects of raw milk, powder quality and storage conditions of UHT milk on its physico-chemical attributes and flavour. Int. Dairy J., v. 7, n. 2-3, p. 129-140, 1996.

[8] DATTA, N.; DEETH, H.C. Diagnosing the cause of proteolysis in UHT milk. Lebensmittel-Wissenschaft and Technologie, v. 36, n. 2, p. 173-182, 2003.

[9] ENRIGHT, E.; BLAND, A.P.; NEEDS; E.C.; KELLY, A.L. Proteolysis and physicochemical changes in milk on storage as affected by UHT treatment, plasmin activity and KIO3 addition. Int. Dairy J., v. 9, n. 9, p. 581-591, 1999.

[10] FAIRBAIRN, D.J.; LAW, B.A. Proteinases of psychrotrophic bacteria: their production, properties, effects and control. J. Dairy Res., v. 53, p. 139-177, 1986.

[11] FUKUDA, P.S.; RÖIG, M.S.; PRATA, F.L. Metodologia quantitativa para determinação espectrofotométrica de ácido siálico em leite. In: CONGRESSO NACIONAL DE LATICÍNIOS, 12, 1994, Juiz de Fora, Anais do XII Congresso Nacional de Laticínios, p.114-119.

[12] FUKUDA, S.P. Aplicação do método de ninidrina ácida como teste de "screening" de plataforma para a detecção de adição de soro ao leite. Cienc. Tecnol. Aliment., v. 16 , n. 1, p. 52-56, 1996.

[13] HARDHAM, J.F. Effect of protein standardization of milk by addition of UF milk permeate on the composition and storage stability of UHT milk. Australian J. Dairy Technol., v. 53, n. 1, p. 22-27, 1998.

[14] HARWALKER, V.A. Age gelation of sterilized milks. In:
Fox, P.F. (Ed) Advanced Dairy Chemistry - 1: Proteins. London: Elsevier, 1992, p. 691-734.

[15] International Commission on Microbiological Specification for Foods. APPCC na qualidade e segurança microbiológica de alimentos. São Paulo: Varela, 1997. 77 p.

[16] KELLY, A.L.; FOLEY, J. Proteolysis and storage of UHT milk as influenced by milk plasmin activity, plasmin/ $\beta$-lactoglobulin complexation, plasminogen activation and somatic cell count. Int. Dairy J., v. 7, p. 411-420, 1997.

[17] KODAK, H.R.; ZADOW, J.G. Age gelation of UHT whole milk as influenced by storage temperature. Australian J. Dairy Technol., v. 40, n. 1, p. 12-21, 1985.

[18] KOHLMANN, K.L.; NEILSON, S.S.; LADISCH, M.R. Effect of serine proteolytic enzymes (trypsin and plasmin), trypsin inhibitor and plasminogen activator addition to ultra-high temperature processed milk. J. Dairy Sci., v. 71, p. 1728-1739, 1988.

[19] KONING, P.J.; KAPER, J.; ROLLENA, H.S.; DRIESSEN, F.M. Age-thinning and gelation in unconcentrated and concentrated UHT-sterilized skim milk: effect of native milk proteinase. Netherlands Milk and Dairy J., v. 39, n. 2, p. 71-87, 1985.

[20] MARIS, P. Regulatory procedures for disinfectants in Europe. Int. Biodeterioration and Biodegradation, v. 41, n. 3/4, p. 297-301, 1998.

[21] McKELlER, R.C., FROEHLICH, D.A., BUTLER, G. CHOLETTE, H., CAMPBELL, C. The effect of uncooled storage on proteolysis bitterness and apparent viscosity in ultra-high-temperature milk. Canadian Inst. Food Sci. and Technol. J., v. 17, n. 1, p. 14-17, 1984.

[22] MITCHEL, G.E.; EWINGS, K.N. Quantification of bacterial proteolysis causing gelation in UHT-treated milk. New Zealand J. Dairy Sci. and Technol., v. 20, p. 65-76, 1985.

[23] MUIR, D.D. The fresh-life of dairy products: 1. Factors influencing raw milk and fresh products. J. Society of Dairy Technol., v. 49, n. 1, p. 24-32, 1996.

[24] NIEUWENHUIJSE, J.A. Changes in heat-treated milk products during storage. In: International Dairy Federation. Heat-induced changes in milk. Brussels: IDF. 1995, p. 231-255.

[25] ORTIN-RODRIGUEZ, L.; SANCHEZ-ALGABA, T. Gelación de la leche UHT: acido siálico libre e amoniaco. Alimentaria, v. 27, n. 213, p.15-20, 1990.

[26] PRENTICE, J.H. Dairy Rheology: A concise guide. Cambridge: VCH Publishers. 1992.

[27] REZENDE, N.C.M.; ROSSI JÚNIOR, O.D.; NADER FILHO, A.; AMARAL, L.A. do. Ocorrência de microrganismos indicadores em leite UHT ("ultra-high temperature") integral. Rev. Bras. Ciênc. Vet., v. 7, n. 1, p. 58-60, 2000.

[28] ROBINSON, R.K.; PHILL, M.A.D. Microbiologia Lactológica. Zaragoza: Acribia, 1987.

[29] SANTOS, M.V.; LARANJA da FONSECA, L.F. Importância e efeito de bactérias psicrotróficas sobre a qualidade do leite. Hig. Aliment., v. 15, n. 82, p. 13-19, 2001.

[30] SILVEIRA, I.A.; CARVALHO, E.P; TEIXEIRA, D. Influência de microrganismos psicrotróficos sobre a qualidade do leite cru refrigerado. Uma revisão. Higiene Alimentar, v. 12, n. 55, p. 21-27, 2000. 
[31] SNOEREN, T.H.M.; VAN RIEL, J.A.M.; BOTH, P. Proteolysis during the storage of UHT-sterilized whole milk 1. Neth. Milk Dairy J., v. 33, p. 31-39, 1979.

[32] SNOEREN, T.H.M.; J.A.M.; BOTH, P.. Proteolysis during the storage of UHT-sterilized whole milk 2. Neth. Milk Dairy J., v. 35, p. 113-119, 1981.

[33] SOLIS, C.S. Gestão e certificação da qualidade de sistemas alimentares integrados. Hig. Aliment., v. 13, n. 61, p. 91-98, 1999.

[34] SØRHAUG, T.; STEPANIAK, L. Psychrotrophs and their enzymes in milk and dairy products: Quality aspects.
Trends in Food Science \& Technology, v. 8, p. 35-40, 1997.

[35] SUR, A.; JOSHI, V.K. Changes in viscosity, pH, oxygen content, sedimentation characteristics and fat separation in UHT milk during storage. Indian J. Dairy Sci., v. 42, n. 1, p.130-131, 1989.

\section{6 - AGRADECIMENTOS}

Agradecemos à FAPESP, pela bolsa de estudo e pelo auxílio à pesquisa concedidos para a realização deste trabalho. 